\title{
Preventing Loss of Femoral Periprosthetic Bone Mineral Density in Cementless Total Hip Arthroplasty Using a Tapered Wedge Stem in Patients With Osteoporosis Treated With Denosumab: a Retrospective, Cohort Study
}

Keiji Kamo ( $\square$ keiji-kamo@par.odn.ne.jp)

Akita Rosai Hospital: Akita Rosai Byoin https://orcid.org/0000-0002-9967-7016

Hiroaki Kijima

Akita University: Akita Daigaku

Koichiro Okuyama

Akita Rosai Hospital: Akita Rosai Byoin

Tetsuya Kawano

Akita University: Akita Daigaku

Nobutoshi Seki

Akita Rosai Hospital: Akita Rosai Byoin

Chie Sato

Akita Rosai Hospital: Akita Rosai Byoin

Tadahito Kido

Akita Rosai Hospital: Akita Rosai Byoin

Mitsuho Chiba

Akita Rosai Hospital: Akita Rosai Byoin

Naohisa Miyakoshi

Akita University: Akita Daigaku

Yoichi Shimada

Akita University: Akita Daigaku

\section{Research Article}

Keywords: Bone mineral density (BMD), total hip arthroplasty (THA), surgery, femoral periprosthetic

Posted Date: July 28th, 2021

DOl: https://doi.org/10.21203/rs.3.rs-736895/v1 
License: (c) (i) This work is licensed under a Creative Commons Attribution 4.0 International License. Read Full License 


\section{Abstract}

Background: Bone mineral density (BMD) of the proximal femur around the stem decreases due to stress shielding after cementless total hip arthroplasty (THA). When severe stress shielding occurs, the risk of periprosthetic femoral fractures increases, and this bone loss can also increase the difficulty of future revision THA. Denosumab is known to improve the quality and strength of cortical bone in the proximal femurs of patients with osteoporosis. The purpose of this study was to investigate whether denosumab prevents loss of proximal femoral periprosthetic BMD in cementless THA using a tapered wedge stem in patients with osteoporosis.

Methods: Sixty-three consecutive patients who had undergone unilateral primary THA using a tapered wedge stem were included in this retrospective study. Twenty-four patients who received denosumab for osteoporosis were the denosumab group, and the 39 without denosumab were the control group. At 2 weeks, 6 months, and 12 months after THA, bone turnover markers and femoral periprosthetic BMD were measured.

Results: BMD in zone 1 was significantly increased from baseline at both 6 and 12 months after THA in the denosumab group and significantly decreased in the control group. BMD in zone 7 was significantly decreased compared to baseline at both 6 and 12 months after THA in the control group, but not in the denosumab group. The use of denosumab for THA patients with osteoporosis was independently related to preventing loss of periprosthetic BMD of the femur at 12 months after surgery in zones 1 and 7 on multivariate analysis.

Conclusions: Denosumab significantly increased proximal femoral periprosthetic BMD in zone 1 and prevented loss of BMD in zone 7 in patients with osteoporosis after cementless THA using a tapered wedge stem at both 6 and 12 months after surgery.

\section{Introduction}

The proportion of elderly people is increasing globally. The prevalence of degenerative or traumatic hip disorders requiring surgical intervention is higher in the elderly population, and it is assumed that the number of older patients who choose to undergo total hip arthroplasty (THA) to improve their quality of life will increase $[1,2]$. Though THA is one of the most successful surgeries, it has several problems. The bone mineral density (BMD) of the proximal femur around the stem decreases due to stress shielding after cementless THA [3, 4]. It has been reported that female patients with low systemic BMD and high bone resorption marker levels show greater periprosthetic proximal femoral bone loss [5]. When severe stress shielding occurs, the risk of periprosthetic femoral fractures increases [6-8]. Furthermore, this bone loss can also increase the difficulty of future revision THA [7]. Several studies have reported that the loss of BMD in the proximal femur around the stem is reduced by bone antiresorptive therapies [9-13]. However, the preventive effect of bisphosphonates on the loss of BMD around the proximal stem is limited [14]. Denosumab is a fully human monoclonal antibody against RANK ligand (receptor activator 
of nuclear factor kappa-B ligand), the key mediator of the formation, activation, and survival of osteoclasts [15]. In the FREEDOM (Fracture REduction Evaluation of Denosumab in Osteoporosis every 6 Months) study, denosumab significantly increased dual X-ray absorptiometry (DXA) BMD not only at trabecular bone, but also at cortical bone. This positive effect of denosumab on cortical BMD has not been observed with other antiresorptive therapies for patients with osteoporosis [15]. Therefore, denosumab may be more effective for reducing the loss of femoral BMD around the stem than bisphosphonates. However, there have been few reports of the preventive effect of denosumab on the loss of femoral periprosthetic BMD in cementless THA for patients with osteoporosis. The purpose of this study was to evaluate the effect of denosumab on femoral periprosthetic BMD after cementless THA using a tapered wedge stem in patients with osteoporosis.

\section{Materials And Methods}

This retrospective, cohort study was approved by the Ethics Committee of the authors' affiliated institution. Informed consent was obtained from all participants. A total of 66 consecutive patients who had undergone unilateral primary THA using a tapered wedge stem (Anthology, Smith and Nephew, Inc., Memphis, TN, USA, or Accolade II, Stryker Orthopaedics, Mahwah, NJ, USA) by the anterolateral approach in the supine position from May 2016 to February 2020 at one institution were retrospectively reviewed. Of these 66 patients, 27 patients with osteoporosis received denosumab before or after THA. The exclusion criteria included history of previous surgery of the ipsilateral hip, evidence of secondary osteoporosis, rheumatoid arthritis or any other inflammatory arthritis, and treatment with corticosteroids. Three of 27 patients with osteoporosis who received denosumab were excluded because they had rheumatoid arthritis. The denosumab group included 24 patients, with 1 patient who received denosumab a year before THA, and 23 patients who received denosumab from 1 to 3 weeks after THA. The reasons for undergoing THA included osteoarthritis (20 cases) and hip fracture (4 cases) in the denosumab group. All denosumab group patients received $0.75 \mu \mathrm{g}$ of eldecalcitol daily to prevent hypocalcemia. The 24 patients with osteoporosis who received denosumab were compared to 39 patients who underwent cementless THA without receiving denosumab at the same institution during the same period. The reasons for undergoing THA in the control group included osteoarthritis (36 cases) and osteonecrosis of the femoral head (3 cases).

All 63 participants were assessed for osteoporosis preoperatively or at 2 weeks after THA by measuring $\mathrm{BMD}$ of the lumbar spine in the anteroposterior view and determining the presence of a fragility fracture in either the lumbar spine or the proximal femur [16]. All of the patients in the denosumab group and 5 patients in the control group had osteoporosis. In the control group, there were 9 patients who were taking medication for osteoporosis before THA: 4 patients received risedronate, 3 patients received $0.75 \mu \mathrm{g}$ of eldecalcitol, 1 patient received ibandronate and $0.75 \mu \mathrm{g}$ of eldecalcitol, and 1 patient received a selective estrogen receptor modulator (SERM). All of the patients in this study underwent DXA (QDR-4500SL, Hologic Inc., Marlborough, MA, USA) to measure femoral periprosthetic BMD 2 weeks, 6 months, and 12 months after THA. BMD measurements around the stem were measured for each of the 7 regions of interest described by Gruen [17] (Fig. 1). BMD of the lumbar spine was also measured in the 
anteroposterior side from L2 to L4 by DXA. Bone turnover markers were measured preoperatively for the baseline and then at 6 months and 12 months after surgery. Bone-type alkaline phosphatase (BAP) was measured as a bone formation marker, and tartrate-resistant acid phosphatase-5b (TRACP-5b) was measured as a bone resorption marker. Radiographic evaluation of the hip joint for loosening of the femoral stem was performed. The canal flare index (CFI) according to Noble et al. [18] was also measured preoperatively on the femur of the operative side. The CFI was determined as the width of the femoral canal $20 \mathrm{~mm}$ above the mid-trochanteric line divided by the canal width at the isthmus [18].

\section{Statistical analysis}

To compare the baseline characteristics of the patients in the 2 groups, the chi-squared test was used for comparisons of categorical variables, whereas Mann-Whitney's $U$ test was used for continuous variables. The mean \% changes of BMD around the stem and of bone turnover markers (BAP, TRACP-5b) were evaluated in each of the 2 groups by Friedman's test. Post hoc comparisons were performed using the Bonferroni correction for multiple comparisons. Multivariate analysis was also performed to identify factors related to BMD preservation at the proximal femur in zone 1 and zone 7 at 12 months after THA. All statistical analyses were performed using R software, version 3.6.3 (R Foundation for statistical Computing, Vienna, Australia). Probability values $<0.05$ were considered significant.

\section{Results}

Baseline demographic and clinical characteristics are shown in Table 1. The mean age at baseline was 73.7 years in the denosumab group and 70.8 years in the control group. The baseline body mass index (BMI) and lumbar spine BMD were significantly lower in the denosumab group than in the control group. There were no significant differences in the type of stem, bone turnover markers, and CFI between the 2 groups. 
Table 1

Baseline characteristics of the patients.

\begin{tabular}{|c|c|c|c|}
\hline & Denosumab $(\mathrm{N}=24)$ & $\begin{array}{l}\text { Control } \\
(\mathrm{N}=39)\end{array}$ & $P$ value \\
\hline Age (years), mean $\pm S D$ & $73.7 \pm 9.3$ & $70.8 \pm 10.3$ & 0.44 \\
\hline Range (years) & $58-91$ & $48-86$ & \\
\hline Sex (male : female) & $1: 23$ & $4: 35$ & 0.73 \\
\hline $\mathrm{BMI}\left(\mathrm{kg} / \mathrm{m}^{2}\right)$, mean $\pm \mathrm{SD}$ & $22.0 \pm 2.7$ & $25.6 \pm 4.3$ & $<0.01$ \\
\hline Type of stem (Anthology : Accolade区) & $10: 14$ & $22: 17$ & 0.29 \\
\hline Osteoporosis (number) & 24 & 5 & \\
\hline Drug for osteoporosis & DSM + Eld 24 & $\begin{array}{l}\text { RIS 4, Eld 2, } \\
\text { IBA + Eld 1, SERM } 1\end{array}$ & \\
\hline Lumber Spine BMD $\left(\mathrm{g} / \mathrm{cm}^{2}\right)$, mean $\pm S D$ & $0.73 \pm 0.14$ & $0.98 \pm 0.18$ & $<0.0001$ \\
\hline $\mathrm{BAP}(\mu \mathrm{g} / \mathrm{l})$, mean $\pm \mathrm{SD}$ & $15.4 \pm 6.5$ & $16.9 \pm 5.8$ & 0.44 \\
\hline TRACP-5b (mU/dl), mean \pm SD & $526 \pm 204$ & $566 \pm 213$ & 0.78 \\
\hline Canal Flare Index (CFI), mean \pm SD & $3.42 \pm 0.61$ & $3.57 \pm 0.69$ & 0.46 \\
\hline
\end{tabular}

Figure 2 shows the mean \% change of BMD around the femoral stem by Gruen's zone. The mean \% change of BMD in zone 1 was significantly higher at both 6 and 12 months after THA than at baseline in the denosumab group, but significantly lower in the control group. There was a significant decrease of BMD in zone 7 compared to baseline at both 6 and 12 months in the control group, but not in the denosumab group. Figure 3 shows the mean \% change of bone turnover markers. Both the bone formation marker (BAP) and the bone resorption marker (TRACP-5b) were significantly lower 6 and 12 months after surgery than at baseline in the denosumab group. There were no significant differences in bone turnover markers in the control group. On radiographic evaluation of the hip joint, there was no stem loosening in any patients in both the denosumab group and the control group 6 and 12 months after THA. On multivariate analysis, use of denosumab was an independent factor related to change in periprosthetic proximal BMD of the femur in zone 1 (Table 2) and zone 7 (Table 3) at 12 months after THA. 
Table 2

Multiple regression analysis for factors affecting \%BMD change in Zone1 at 12 months after THA.

\begin{tabular}{|lllll|}
\hline & $\begin{array}{l}\text { Regression } \\
\text { coefficient }\end{array}$ & 95\% confident interval & P value & $\mathbf{R}^{\mathbf{2}}$ \\
\hline Model summary & & & & \\
\hline Age & 0.10 & -0.21 to 0.41 & 0.51 & \\
\hline BMl & 0.08 & -0.74 to 0.89 & 0.851 \\
\hline Lumber BMD & 1.34 & -17.7 to 20.4 & 0.89 & \\
\hline use of denosumab & 21.6 & 14.3 to 29.0 & $<0.0001$ & \\
\hline BMl: body mass index, BMD: bone mineral density & & \\
\hline
\end{tabular}

Table 3

Multiple regression analysis for factors affecting \%BMD change in Zone7 at 12 months after THA.

\begin{tabular}{|lllll|}
\hline & $\begin{array}{l}\text { Regression } \\
\text { coefficient }\end{array}$ & 95\% confident interval & P value & $\mathbf{R}^{\mathbf{2}}$ \\
\hline Model summary & & & $<0.0001$ & 0.29 \\
\hline Age & 0.01 & -0.47 to 0.49 & 0.97 & \\
\hline BMI & -0.32 & -1.59 to 0.94 & 0.61 & \\
\hline Lumber BMD & 9.15 & -20.4 to 38.7 & 0.54 \\
\hline use of denosumab & 25.2 & 13.8 to 36.5 & $<0.0001$ & \\
\hline BMl: body mass index, BMD: bone mineral density & & \\
\hline
\end{tabular}

\section{Discussion}

The present study demonstrated the preventive effect of denosumab on loss of femoral periprosthetic BMD in zone 1 and zone 7 in cementless THA using a tapered wedge stem in patients with osteoporosis 12 months after surgery. Moreover, BMD in zone 1 was significantly increased from baseline at both 6 and 12 months after THA in the denosumab group. This result was consistent with a previous study using a tapered wedge uncemented stem [19]. Aro et al. showed that denosumab significantly decreased bone loss in the femoral neck (zone 7) and increased periprosthetic BMD in the greater trochanteric region (zone 1) [19]. Nagoya et al. reported that denosumab increased the $\%$ change in periprosthetic BMD at zone 7 by an average of $7.3 \%$, but it did not increase at zone 1 in patients with cementless THA using a ZweyMüller-type stem [13]. This discrepancy was considered due to the difference in type of cementless stem between a tapered wedge stem and a ZweyMüller-type stem. 
The periprosthetic BMD of the proximal femoral stem was significantly decreased in zone 7 even with the use of bisphosphonates, though bisphosphonates prevented some loss of proximal periprosthetic BMD in zone 1 and zone 7 compared to the control group not given bisphosphonates [9, 11, 20]. In the present study using denosumab, there was no significant decrease of BMD in zone 7 compared to baseline after THA, and denosumab may be more effective in preventing periprosthetic proximal femoral BMD than bisphosphonates. In addition, this study showed that, on multivariate analysis, the use of denosumab was an independent factor related to change in periprosthetic proximal BMD of the femur in zone 1 and zone 7. Poole et al. reported that denosumab significantly increased proximal femoral cortical mass surface density, as well as thickness, in women with osteoporosis [21]. The positive effect of denosumab on cortical bone in the proximal part of the femur is not seen with bisphosphonates. The antiresorptive effect of bisphosphonates is not sufficient in cortical bone, because concentrations of bisphosphonates are lower in cortical bone than in trabecular bone $[22,23]$. In contrast, denosumab circulates freely to bone surfaces and into remodeling compartments where it inhibits osteoclastogenesis and can thus inhibit remodeling more rapidly and markedly than alendronate in cortical bone [23]. Since there is greater cortical bone mass than cancellous bone mass in the proximal part of the femur after cementless THA using a tapered wedge stem, use of denosumab, which has a high effect on cortical bone, is considered effective for maintaining periprosthetic BMD. In addition, Zebaze et al. reported that denosumab reduced cortical porosity of the proximal femoral shaft, resulting in increased mineralized matrix volume and improved strength [24]. These effects of denosumab may reduce the risk of periprosthetic femoral fractures after cementless THA.

There are several limitations in this study. First, the present study had a small sample and was retrospective. Further randomized or prospective studies with large sample sizes are needed to investigate the preventive effect of denosumab on the loss of femoral periprosthetic BMD using a tapered wedge stem in patients with osteoporosis. Second, this study had a short-term follow-up period. The BMD in the calcar region continued to decrease faster than would be expected from normal ageing up to 14 years after THA using a tapered uncemented stem [25]. However, it was reported that BMD decreased markedly in the proximal part of the femur during the first operative year, and the bone loss was minimal at only a few percentages per year after the first postoperative year [26]. Thus, it is important to prevent loss of BMD of the proximal femur around the stem within 12 months after THA. Third, some patients in the control group were taking medication for osteoporosis, which may have affected the results of this study. However, denosumab was shown to be effective in preventing loss of BMD in the proximal part of the femoral stem even though some of the patients in the control group may have had a positive effect from the drugs they took for osteoporosis in the present study.

In conclusion, denosumab significantly increased proximal femoral periprosthetic BMD in zone 1 and prevented loss of BMD in zone 7 in patients with osteoporosis after cementless THA using a tapered wedge stem at both 6 and 12 months after surgery. The use of denosumab for THA patients with osteoporosis was an independent factor related to preventing loss of periprosthetic proximal BMD of the femur in zone 1 and zone 7 on multivariate analysis. 


\section{Abbreviations}

BMD

Bone mineral density

THA

Total hip arthroplasty

RANK ligand

receptor activator of nuclear factor kappa-B ligand

FREEDOM

Fracture REduction Evaluation of Denosumab in Osteoporosis every 6 Months

DXA

Dual X-ray absorptiometry

DSM

Denosumab

RIS

Risedronate

Eld

Eldecalcitol

IBA

Ibandronate

\section{SERM}

Selective estrogen receptor modulator

BAP

Bone-type alkaline phosphatase

TRACP-5b

Tartrate-resistant acid phosphatase-5b

CFI

Canal flare index

BMI

Body mass index

\section{Declarations}

\section{Availability of date and materials}

The datasets used and/or analyzed during the current study are available from the correspomding author on reasonable request.

\section{Acknowledgments}

Not applicable. 


\section{Funding}

Not applicable.

Author information

Affiliations

Akita Rosai Hospital, Odate, Japan

Keiji Kamo, Koichiro Okuyama, Nobutoshi Seki, Chie Sato, Tadahito Kido, Mitsuho Chiba

Department of Orthopedic Surgery, Akita University Graduate School of Medicine, Akita, Japan

Hiroaki Kijima, Tetsuya Kawano, Naohisa Miyakoshi, Yoichi Shimada

\section{Contributions}

$\mathrm{KK}, \mathrm{HK}, \mathrm{TK}, \mathrm{NM}$ and $\mathrm{YS}$ contributed to the study conception and design. Date collection and analysis were performed by KK, KO, NS, CS, TK and MC. KK and HK wrote the manuscript. The authors read and approved the final manuscript.

\section{Corresponding author}

Correspondence to Keiji Kamo.

\section{Ethics declarations}

\section{Ethics approval and consent to participate}

This study was approved by the Ethics Committee of Akita Rosai Hospital. Informed consent was obtained from all participants.

Consent for publication

Written informed consent was obtained from the patients for publication.

\section{Competing interests}

The authors declare that they have no competing interests.

\section{References}

1. Culliford DJ, Maskell J, Beard DJ, Murray DW, Price AJ, Arden NK. Temporal trends in hip and knee replacement in the United Kingdom: 1991 to 2006. J Bone Joint Surg Br. 2010 Jan;92(1):130-5. 
2. Yuasa T, Maezawa K, Nazawa M, Kaneko K. Cementless total hip arthroplasty in patients aged $\geqq 80$ years. J Orthop.2016 Jan 22;13(1):29-32.

3. Engh CA, Bobyn JD, Glassman AH. Porous-coated hip replacement. The factors governing bone ingrowth, stress shielding, and clinical results. J Bone Joint Surg Br. 1987 Jan;69(1):45-55.

4. Bobyn JD, Mortimer ES, Glassman AH, Engh CA, Miller JE, Brooks CE. Producing and avoiding stress shielding. Laboratory and clinical observations of noncemented total hip arthroplasty. Clin Orthop Relat Res. 1992 Jan;(274):79-96.

5. Alm JJ, Mäkinen TJ, Lankinen P, Moritz N, Vahlberg T, Aro HT. Female patients with low systemic BMD are prone to bone loss in Gruen zone 7 after cementless total hip arthroplasty. Acta Orthop. 2009 0ct;80(5):531-7.

6. Haddad FS, Masri BA, Garbuz DS, Duncan CP. The prevention of periprosthetic fractures in total hip and knee arthroplasty. Orthop Clin North Am. 1999;30(2):191-207.

7. Knutsen AR, Lau N, Longjohn DB, Ebramzadeh E, Sangiorgio SN. Periprosthetic femoral bone loss in total hip arthroplasty: systematic analysis of the effect of stem design. Hip Int. 2017 Feb 21;27(1):26-34.

8. Lindahl H. Epidemiology of periprosthetic fracture around a total hip arthroplasty. Injury. 2007 Jun;38(6):651-4.

9. Yamasaki S, Masuhara K, Yamaguchi K, Nakai T, Fuji T, Seino Y. Risedronate reduces postoperative bone resorption after cementless total hip arthroplasty. Osteoporos Int. 2007 Jul;18(7):1009-15.

10. Iwamoto N, Inaba Y, Kobayashi N, Yukizawa Y, Ike H, Ishida T, Saito T. The effectiveness of mono or combined osteoporosis drug therapy against bone mineral density loss around femoral implants after total hip arthroplasty. J Bone Miner Metab. 2014 Sep;32(5):539-44.

11. Sköldenberg OG, Salemyr MO, Bodén HS, Ahl TE, Adolphson PY. The effect of weekly risedronate on periprosthetic bone resorption following total hip arthroplasty: a randomized, double-blind, placebocontrolled trial. J Bone Joint Surg Am. 2011 Oct 19;93(20):1857-64.

12. Huang TW, Wang CJ, Shin HN, Chang Y, Huang KC, Peng KT, Lee MS. Bone turnover and periprosthetic bone loss after cementless total hip arthroplasty can be restored by zoledronic acid: a prospective, randomized, openlabel, controlled trial. BMC Musculoskelet Disord. 2017 May 22;18(1):209.

13. Nagoya S, Tateda K, Okazaki S, Koskegawa I, Shimizu J, Yamashita T. Restoration of proximal periprosthetic bone loss by denosumab in cementless total hip arthroplasty. Eur J Orthop Surg Traumatol. 2018. Dec;28(8):1601-7.

14. Muren O, Akbarian E, Salemyr M, Bodén H, Eisler T, Stark A, Sköldenberg O. No effectf risedronate on femoral periprosthetic bone loss following total hip arthroplasty. A 4-year follow-up of 61 patients in a double-blind, randomaized placebo-controlled trial. Acta Orthop. 2015;85(5):569-74.

15. Bolognese MA, TeglbjÓ $\square$ rg CS, Zanchetta JR, Lippuner K, McClung MR, Brandi ML, Høiseth A, Lakatos P, Moffett AH, Lorenc RS, Wang A, Libanati C. Denosumab significantly increase DXA BMD at both 
trabecular and cortical sites: results from the FREEDOM study. J Clin Densitom. 2013 AprJun;16(2):147-53.

16. Soen S, Fukunaga M, Sugimoto T, Sone T, Fujiwara S, Endo N, Gorai I, Shiraki M, Hagino H, Hosoi T, Ohta H, Toneda T, Tomomitsu T. Diagnostic criteria for primary osteoporosis: year 2012 revision. Japanese Society for Bone and Mineral Research and Japan Osteoporosis Society Joint Review Committee for the Revision of the Diagnostic Criteria for Primary Osteoporosis. J Bone Miner Metab. 2013 May;31(3):247-57.

17. Gruen TA, McNeice GM, Amstutz HC. "Modes of failure" of cemented stem-type femoral components: a radiographic analysis of loosening. Clin Orthop Relat Res. 1979 Jun;(141):17-27.

18. Noble PC, Alexander JW, Lindahl LJ, Yew DT, Granberry WM, Tullos HS. The anatomic basis of femoral component design. Clin Orthop Relat Res. 1988 Oct;(235):148-65.

19. Aro HT, Nazari-Farsani S, Vuopio M, Löyttyniemi E, Mattila K. Effect of Denosumab on Femoral Periprosthetic BMD and Early Femoral Stem Subsidence in Postmenopausal Women Undergoing Cementless Total Hip Arthroplasty. JBMR Plus. 2019 Aug;14(10):e10217. 3(.

20. Arabmotlagh M, Pilz M, Warzecha J, Rauschmann M. Changes of femoral periprosthetic bone meniral density 6 years after treatment with alendronate following total hip arthroplasty. $J$ Orthop Res. 2009 Feb;27(2):183-8.

21. Poole KE, Treece GM, Gee AH, Brown JP, McClung MR, Wang A, Libanati C. Denosumab rapidly increases cortical bone in key locations of the femur: a 3D bone mapping study in woman with osteoporosis. J Bone Miner Res. 2015 Jan;30(1):46-54.

22. Roelofs AJ, Stewart CA, Sun S, Błażewska KM, Kashemirov BA, McKenna CE, Russell RG, Rogers MJ, Lundy MW, Ebetino FH, Coxon FP. Influence of bone affinity on the skeletal distribution of fluorescently labeled bisphosphonates in vivo. J Bone Miner Res. 2012 Apr;27(4):835-47.

23. Zebaze RM, Libanati C, Austin M, Ghasem-Zadeh A, Hanley DA, Zanchetta JR, Thomas T, Boutroy S, Bogado CE, Bilezikian JP, Seeman E. Differing effects of denosumab and alendronate on cortical and trabecular bone. Bone. 2014 Feb;59:173-9.

24. Zebaze R, Libanati C, McClung MR, Zanchetta JR, Kendler DL, Høiseths A, Wang A, Ghasem-Zadeh A, Seeman E. Denosumab Reduces Cortical Porosity of the Proximal Femoral Shaft in Postmenopausal Women With Osteoporosis. J Bone Miner Res. 2016 Oct;31(10):1827-34.

25. Bodén HS, Sköldenberg OG, Salemyr MO, Lundberg HJ, Adolphson PY. Continuous bone loss around a tapered uncemented femoral stem: a long-term evaluation with DEXA. Acta Orthop. 2006 Dec;77(6):877-85.

26. Tapaninen $T$, Kröger $H$, Venesmaa P. Periprosthetic BMD after cemented and uncemented total hip arthroplasty: a 10-year follow-up study. J Orthop Sci. 2015 Jul;20(4):657-62.

\section{Figures}




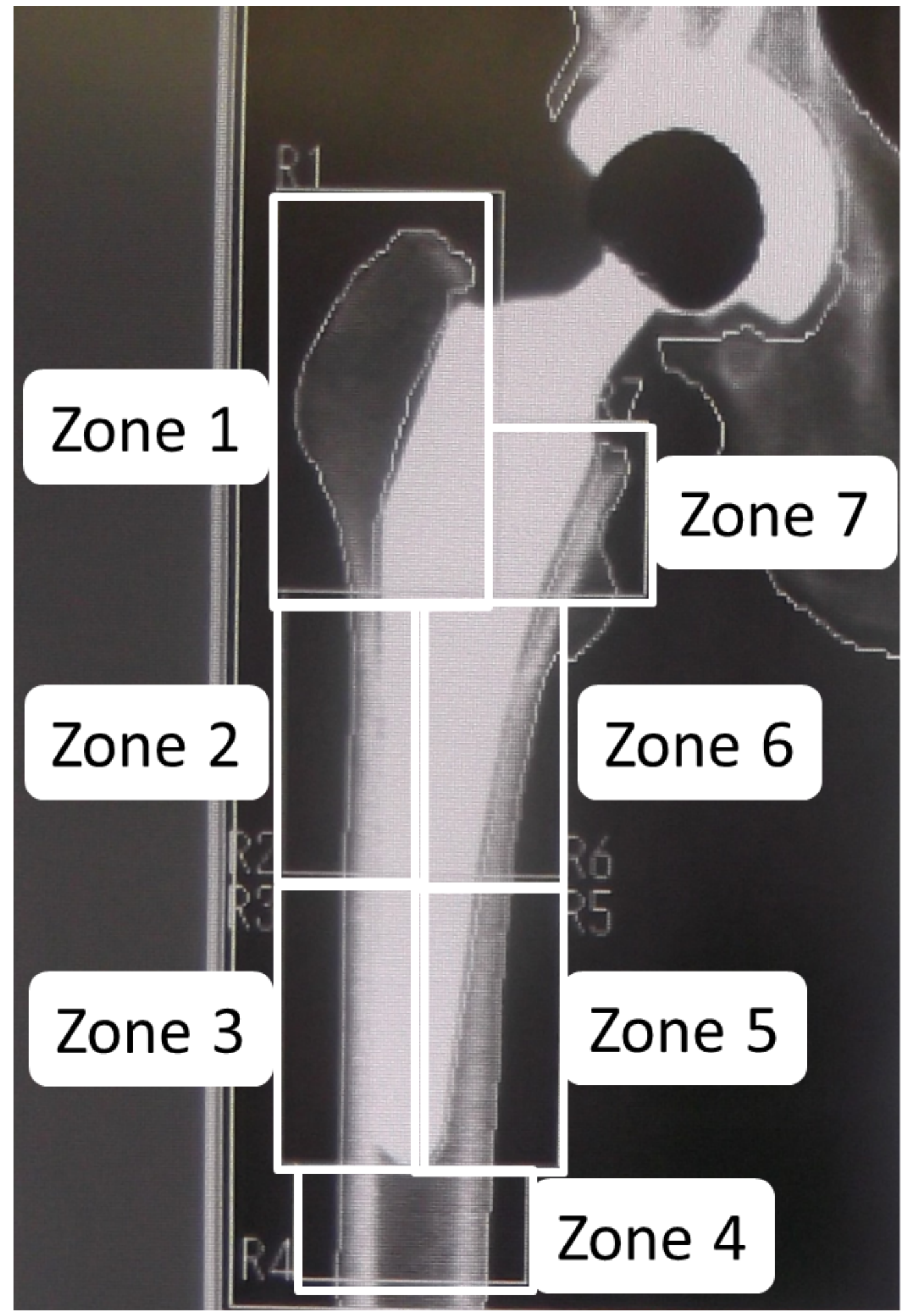

Figure 1

The seven regions of interest according to Gruen`s classification 
Zone 1

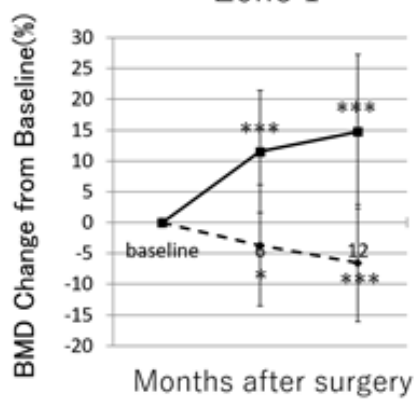

Zone 3

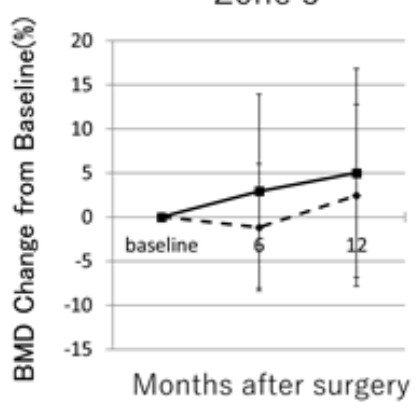

Zone 5

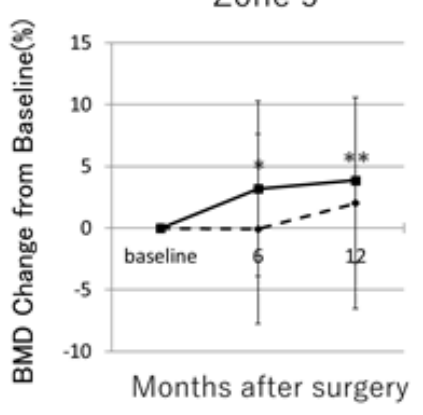

Zone 7

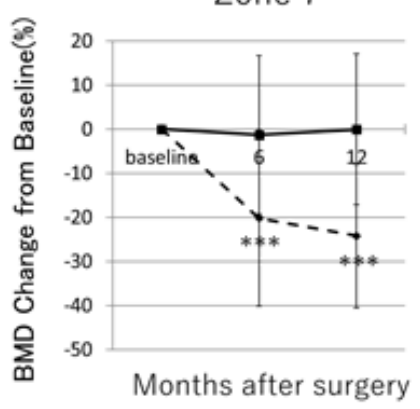

Zone 2

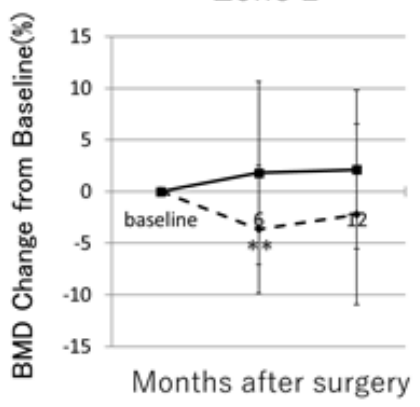

Zone 4

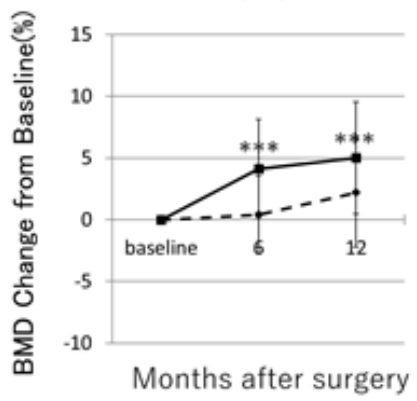

Zone 6

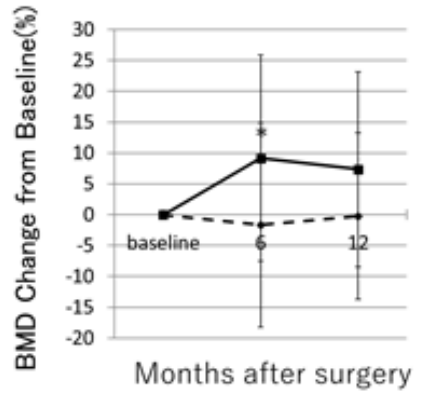

\section{Figure 2}

The mean \% change of bone mineral density (BMD) around the femoral tapered wedge stem. *p<0.05 vs. baseline, ${ }^{* *} p<0.01$ vs. baseline, ${ }^{* *} p<0.001$ vs. baseline BMD: bone mineral density 

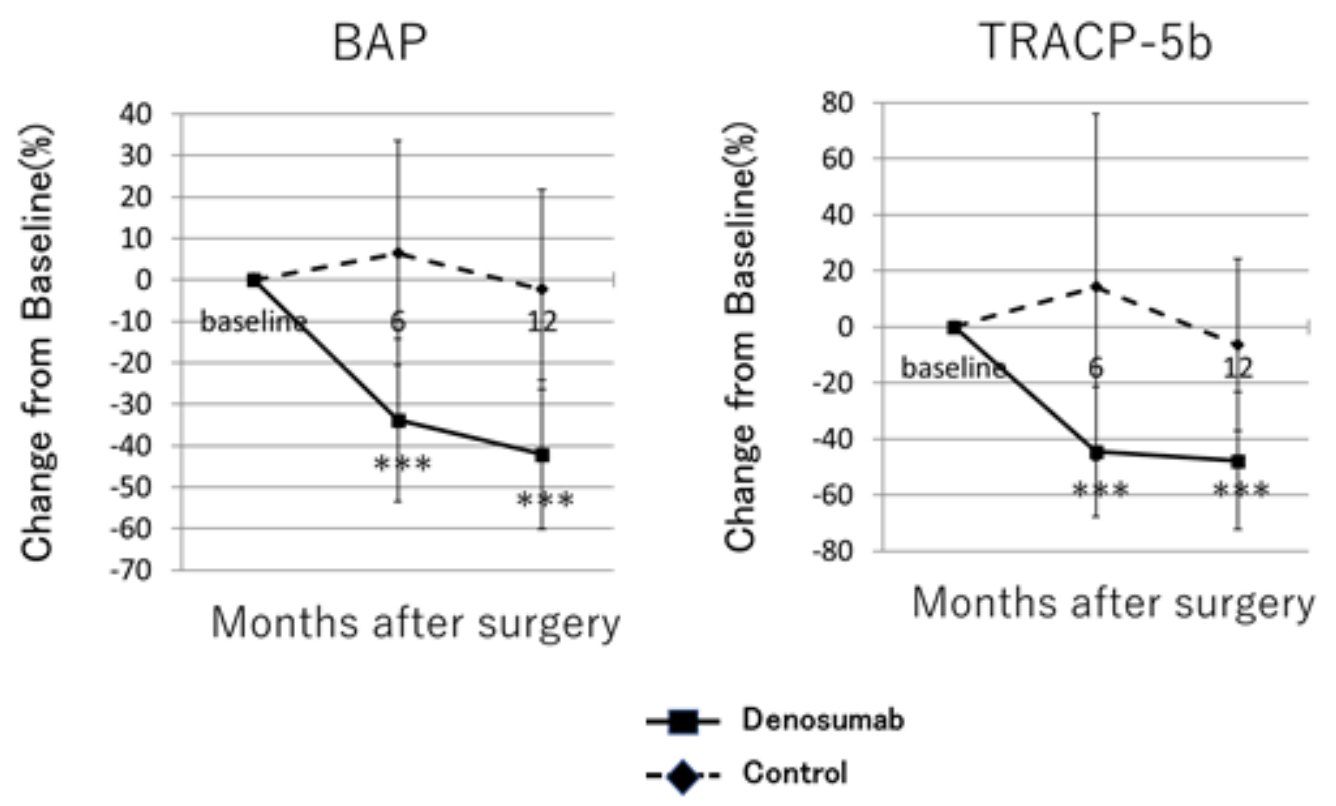

\section{Figure 3}

The mean $\%$ change of bone turnover makers. BAP: bone-type alkaline phosphatase, TRACP-5b: tartrate resistant acid phosphatase- $5 \mathrm{~b},{ }^{\star \star *} \mathrm{p}<0.001$ vs. baseline 